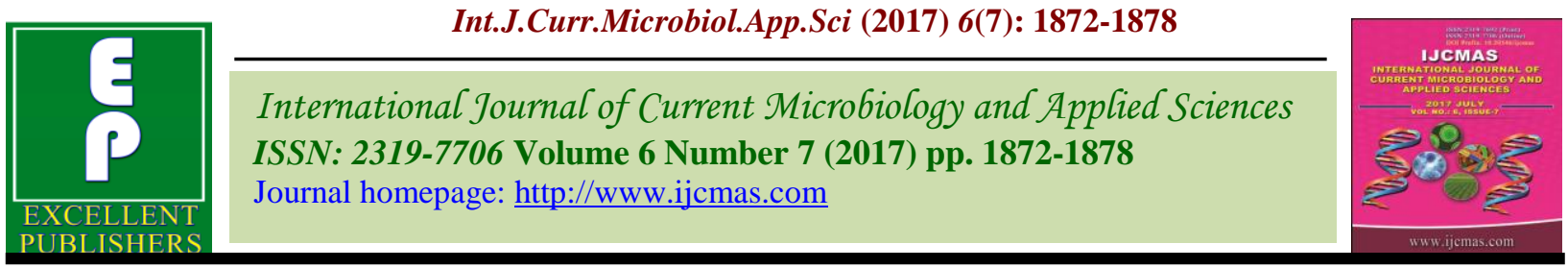

Original Research Article

https://doi.org/10.20546/ijcmas.2017.607.223

\title{
Isolation, Screening and Identification of Lipase Producing Fungi from Oil Contaminated Soil of Shani Mandir Ujjain
}

\author{
Toshi Wadia* and Sudhir Kumar Jain \\ School of Studies in Microbiology, Vikram University, Ujjain (M.P), India \\ *Corresponding author
}

\begin{abstract}
A B S T R A C T
Keywords

Fungi, Lipases, Tributyrin Agar, Aspergillus niger, Penicillium sp., Alternaria sp., Trichoderma $\mathrm{sp.}$

Article Info

Accepted:

19 June 2017

Available Online:

10 July 2017

Lipases are secreted by many fungi, yeasts and bacteria. The suitable habitat to isolate lipase producing microorganisms is the oil contaminated sites. In Ujjain a very famous 'Navgrah-Shani' Temple situated at the Triveni Ghat of Kshipra river, where devotees from all over India come and worship the lord and it is an unique oily habitat for isolation of lipase producing microorganisms. The present study was aimed to isolate, screen and identify the lipase producing fungi from the oil contaminated soil. For isolation standard isolation method was followed, while screening was done on TBA (Tri Butyrin agar) medium. Results revealed that out of total 15 , only five fungi were potent to produce lipase on TBA agar plates and these were used for further investigation. Aspergillus niger, Penicillium sp., Alternaria sp., Trichoderma sp., and Aspergillus flavus were identified according to colony morphology and microscopic observation. In relation to the different test strains, Alternaria sp., and Aspergillus flavus, were found the best among all extracellular lipase producers. Further, due to the fact that these microorganisms can be useful for bioremediation of oil contaminated sites, research is necessary to optimize the fermentative process in order to obtain higher lipase production through such fungal isolates.
\end{abstract}

\section{Introduction}

India is the country full of festivals and rich in temples. In temples various types of religious activities (Puja) are performed by the devotees. Ujjain is the city of Madhya Pradesh in Central India famous for temples. The famous Shani Mandir is situated at the bank of holy river Kshipra. The ritual of praying includes 'Abhishek' i.e., offering oil to the lord which means devotees use oil for the cleansing or purification of the lord's sculpture. Every week several devotees and pilgrims visit the temple, especially for performing this very ritual. This huge amount of oil is then get collected and funnel to the oil tank situated near the temple at the bank of Kshipra river. But due to lack of proper disposal treatment facilities, this oil contaminates the soil of that region, the physiochemical conditions of this region's soil, especially its oil concentration, have an important role in creating its microbial diversity.

Lipases (triacyl glycerol acyl hydrolases E.C. 3.1.1.3) are hydrolytic enzymes that catalyze the hydrolysis of fats and oils to glycerol and fatty acids. Lipases have been the subject of active research on account of their versatile 
applications in different industries now a day but still needs more work for its application for a layman. Lipases with new properties have been widely used in several areas such as medicine, biotechnology, detergent, and bioremediation, still there are substantial interests in developing new microbial lipases. A considerable number of fungal and bacterial lipases have been commercially produced, but fungi are more preferable because fungi generally produce extracellular enzymes which facilitate recovery of the lipase (Reetz, 2002; Colen et al., 2006).

Lipase producing microbes (fungi and bacteria) have been reported from a wide range of environments such as industrial wastes, compost heaps, oilseeds, deteriorated food vegetable oils processing factories and dairy products (Sharma et al., 2001). Molds (Filamentous fungi) are good lipase producers and numerous fungal enzymes are utilized in various food industrial processes (Aravindan et al., 2007). Fungal enzymatic systems among microorganisms have important effects on biodegradation of undesirable compounds, including various oils. Although fungi have been identified in oil contaminated environment for many years, their role was uncertain for various reasons (Singh and Mukhopadhayay, 2012; Gopinath et al., 2013). Microbial enzymes are commercially well accepted due to various characters such as production quantity, genetic modifiability as well as low costs. Several methods have been described to screen for lipase production. Since lipases produced by filamentous fungi are mainly extracellular, extraction and purification of them are relatively easy. This reason may also contribute to the fact that fungal lipases belong to the most important groups of commercial enzymes.

Lipase production by filamentous fungi in a culture medium is dependent on environmental conditions often the presence of an inducer (mostly oil) and the appropriate physiological parameters such as $\mathrm{pH}, \mathrm{NaCl}$ concentration, temperature and dissolved oxygen (Treichel et al., 2010). Optimum cultivation conditions are even more essential to achieve the best yield for extracellular enzyme production. In addition, it is reported that a single lipase showing various distinct biochemical properties can also be obtained if different fermentation procedures are applied for the same fungus (Mateos Diaz et al., 2006). The primary objective of this work is to isolate and identify lipase producing fungiand screen out the best lipase producer among them from the oil contaminated soil at Shanimandir (Ujjain).

\section{Materials and Methods}

\section{Collection of soil samples}

For this purpose, the samples were collected from different sites near the Shani Mandir. All the soil samples collected in the sterilized polythene bags using sterilized spatula and brought to the laboratory. Further, all the samples were mixed to get composite sample for isolation of lipase producing fungi.

\section{Isolation of lipase producing fungi}

Ten gram samples (from each site) were suspended in $250 \mathrm{~mL}$ Erlenmeyer flask containing $100 \mathrm{~mL}$ sterile physiological saline. This was followed by constant and vigorous stirring for $30 \mathrm{mins}$ at $120 \mathrm{rpm}$ to dislodge soil clumps before allowing settling. The supernatant was decanted and a 10-fold serial dilution made from it. Serial dilutions were prepared and $0.1 \mathrm{ml}$ from $10^{-2}$ and $10^{-3}$ dilution was cultivated on Potato Dextrose Agar (PDA) and incubated at $27^{\circ} \mathrm{C}$ for 5 days. Grown fungal colonies were then purified on PDA plates. 


\section{Screening of lipolytic fungal species}

Screening of lipase producing fungi was done using tributyrin as a substrate on agar plates. For this purpose tributyrin agar (HiMedia) was use of following composition: Peptone: 5.0gm; Yeast extract: 3.0gm; Agar agar: 15.0gm; Tributyrin (Glycerol Tributyrate): 10.0ml; Distilled water: $990 \mathrm{ml}$; $\mathrm{pH}: 7.5$. The formation of the clear zone around the colonies indicates the production of lipase. All the isolated fungal culture were inoculated on the TBA plates and incubated at $27^{\circ} \mathrm{C}$ up to 15days. The formation of opaque zones around the colonies is an indication of lipase production by the organisms.

\section{Identification of screened fungi}

After screening, five potent fungal cultures were used for further study and identified by microscopic examination using Lactophenol cotton blue staining technique. Identified fungi were maintained on PDA (Potato Dextrose Agar) medium. Identification of selected fungal culture was followed by laboratory manuals.

\section{Results and Discussion}

In the present work Isolation, Screening and identification of lipase producing fungi from oil contaminated soil of Shani Mandir Ujjain was studied. Soil samples were collected from the oil contaminated soil as per the standard methods and a composite sample was prepared for the isolation of fungi (PhotoPlate-1and 2). Total fifteen fungi were isolated by standard method and out of them only five were found lipase producer (Photoplate 3).The isolated cultures were maintained on the potato dextrose agar (PDA) 4\% (w/v) slants at $27 \pm 1^{\circ} \mathrm{C}$.

For the screening, Tributyrin agar Medium (HiMedia) is used to observe the clear zone around the colony. Maximum lipase production was observed in the fungi Alternaria sp., followed by Aspergillus flavus (Figure 1). After first day of incubation Apsergillus niger did not produce lipase, while small amount of lipase in the form of zone $(1.7 \mathrm{~mm})$ was observed around the Trichoderma sp., colony. After fifth day of incubation maximum lipase production was observed in Aspergillus flavus $(4.3 \mathrm{~mm})$ and minimum was observed in A. niger $(1.4 \mathrm{~mm})$. The similar trend was observed for further $10^{\text {th }}$ and $15^{\text {th }}$ days of incubation.

Variation in the lipase production is also evident in present study (Figure 1) where maximum lipase production was observed after 15 days of incubation in Alternaria sp. and Aspergillus flavus. Lipase from fungi has been exploited as valuable due to its thermal stability, $\mathrm{pH}$ stability, substrate specificity and activity in organic solvents (Gupta et al., 2003).

It is evident from the previous researches that soil contaminated with oils also possesses microbial diversity. These microorganisms are being exploited for their potential as lipase producers. Lipases are widely distributed among plants, animals, and microorganisms especially fungal lipases are being used for diverse applications (Saxena et al., 1999; Sharma et al., 2001; Iftikhar and Hussain, 2002; Singh et al., 2012). Although, lipase producing fungi are present in diverse habitat and isolated by various workers in recent past. According to Thomas et al., 1973, lipase production varies with species for the parameters like optimum temperature, optimum $\mathrm{pH}$ and enzyme specificity. This group of enzymes performs and catalyzesa wide range of reactions such as hydrolysis, inter-esterification, alcoholysis, acidolysis, esterification and aminolysis (Joseph, et al., 2008). The extracellular bacterial lipases are commercially important, because their mass 
production is much easier and also applicable to accelerate the degradation of fatty wastes and polyurethane (Gupta et al., 2003; Jisheng et al., 2005).

Photo Plate.1 Sampling site near Shani temple in Ujjain

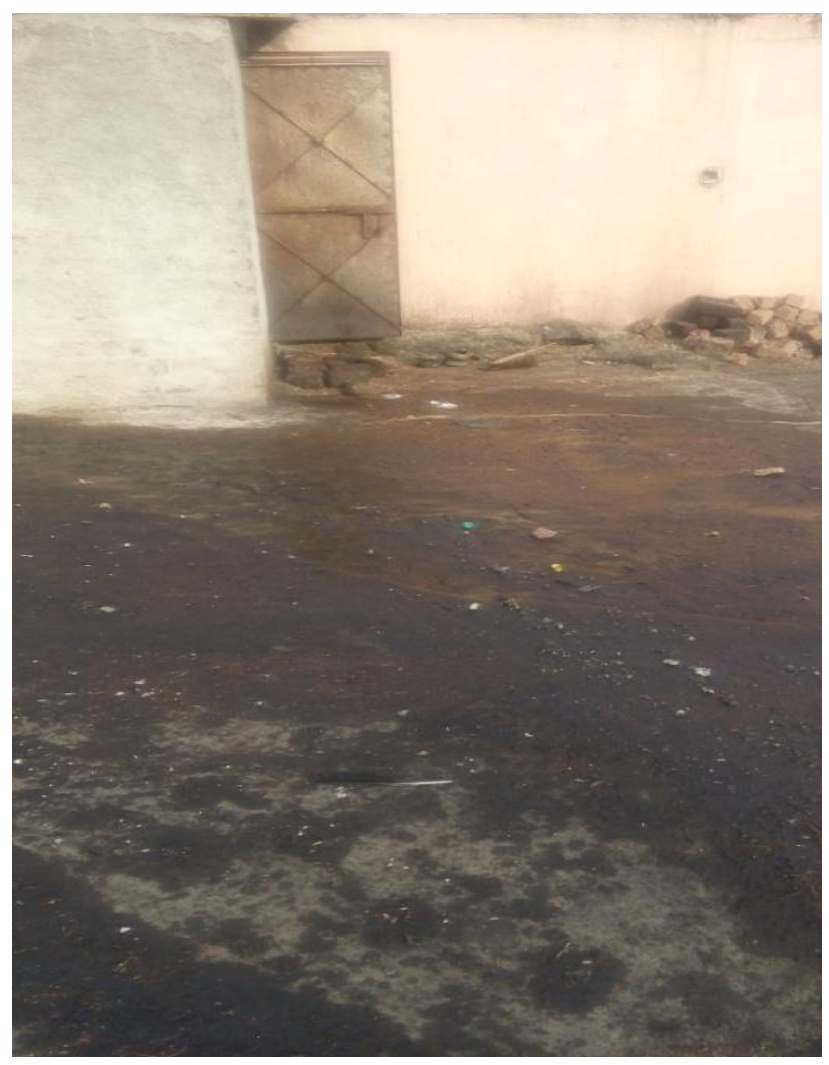

Photo Plate.2 Collection of oil contaminated soil sample

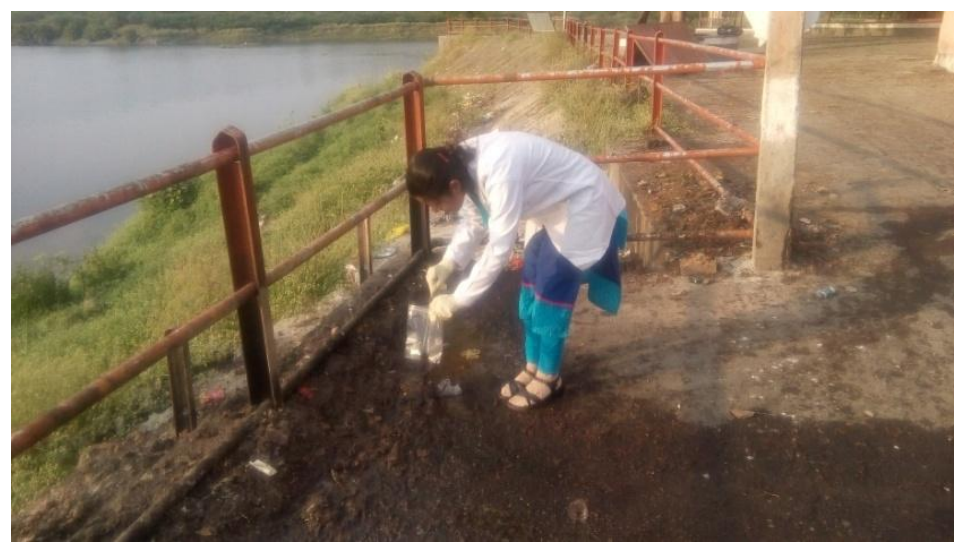


Photo Plate.3 Fungi isolated from the oil contaminated soil

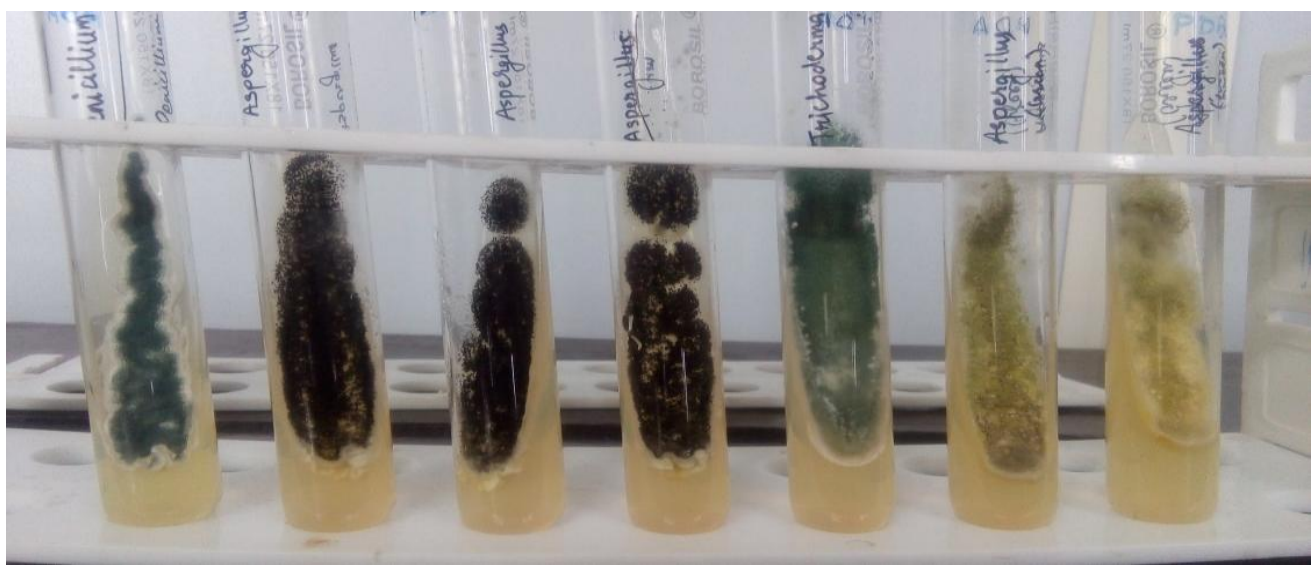

Photo Plate. 3 and 4 Clear zone around the fungal colony

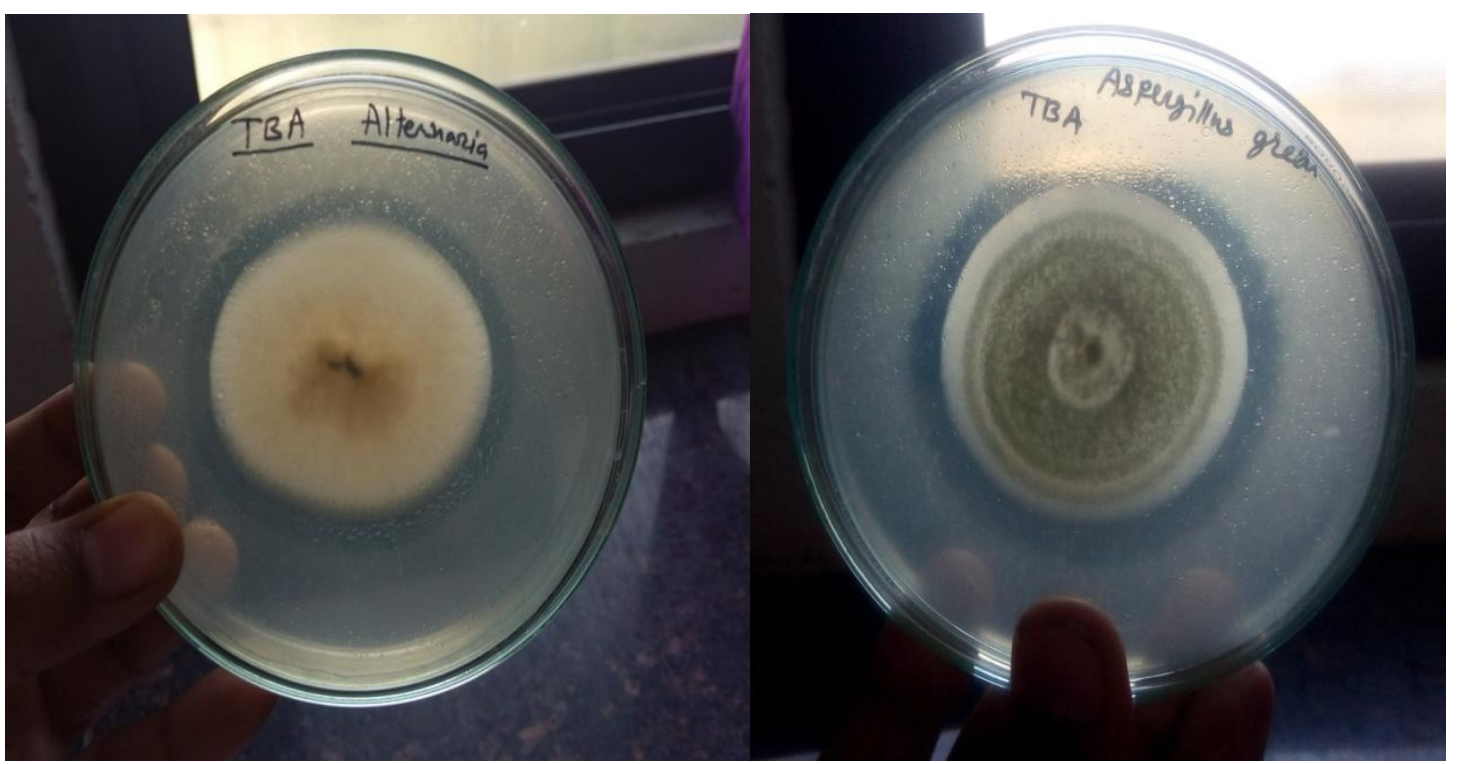

Fig.1 A comparative graph of zone of clearance against different fungi

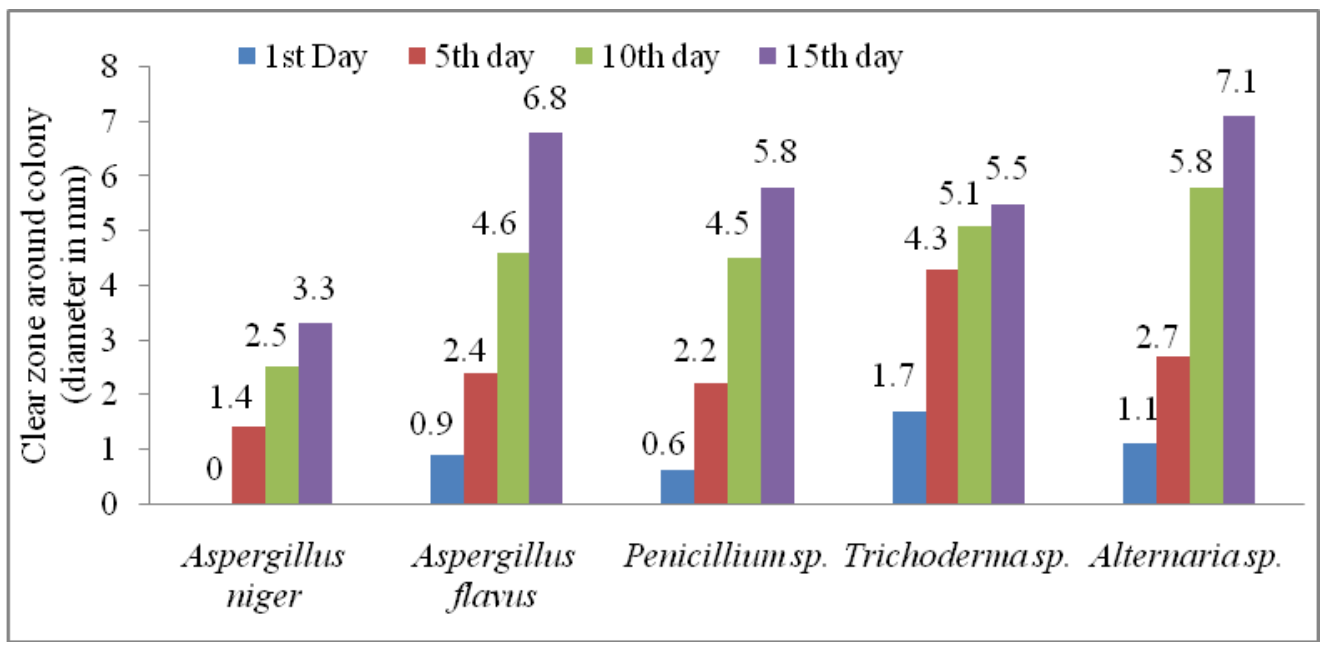


For the screening purpose, simple "Cup-Plate Assay" (Sierra, 1957) is very useful on TBA plates. A clear zone around the fungal colonies indicates lipase production. The three substrates which are mostly used for Cup plate assay are Glycerol tributyrate (1,2,3-Tributyrylglycerol), Tween 80 and Tween 20. If Tweens are used as substrates for lipase, no dyes are required for visualization (Thomson et al., 1999) they give the whiteopaque zones around the colonies (zone of precipitation of calcium salt) when hydrolysis is pointing out either esterase or lipase activity (Gupta, et al., 2003). According to Sarkar et al., 1998, Tributyrin is considered as a most suitable material for screening of lipase producing microorganisms and in present study it was taken into account for screening. Screening and selection of a particular isolate, is a tedious task, especially when commercially competent enzyme yields are to be achieved. It has been reported that, microorganism provide high yields of lipase when organic nitrogen sources are used (Godfredson et al., 1990).

Literature is available that the fungal lipase is comparatively prone to be more thermostable than bacterial lipase. Fungal lipase has benefits over bacterial ones due to the fact that present day technology favors the use of batch fermentation and low cost extraction methods. In this regard, a good number of fungi have been screened for lipase production. Molds are best microbial population for lipase production commercially because these are easily extracted from fermentation processes, safe and easy handling, in addition to the growing potential of the same as the use for the said purposes, in the form of whole cell biocatalysts (Alberton et al., 2010; Andrade et al., 2014). Present study also supports this fact because all isolated fungi are filamentous in nature (Photo Plate 3 and 4). Production of lipases by the fungi is dependent on various parameters such as substrates, optimum $\mathrm{pH}$, temperature etc., and it was reported by previous researchers (Bankole and Joda, 2004; Bhattacharya and Raha, 2004; Negedu et al., 2011).

Lipases are ubiquitous enzymes of considerable physiological significance and industrial potential. So studies to analyze the production of the enzyme from microbial source are essential from the research, environmental and commercial point of view. Lipase-based processing has a promising future. The fungal strains obtained in the present work, showing maximum lipolytic activity could be used commercially for the production of lipases with minimum expenses, to make it available more easily.

\section{References}

Alberton, D., Mitchell, D.A., Cordova, J., Peralta-Zamora, P., Krieger, N. 2010. Production of fermented solid containing lipases of Rhizopus microsporus and its application in the pre-hydrolysis of high-fat dairy wastewater. Food Technol. Biotechnol., 48: 28-35.

Andrade, G.S.S., Carvalho, A.K.F., Romero, C.M., Oliveira, P.C., Castro, H.F. 2014.Mucorcircinelloides whole-cells as a biocatalyst for the production of ethyl esters based on babassu oil. Bioprocess and Biosystems Engi. 37: 2539-2548.

Aravindan, R., Anbumathi, P., Viruthagiri, T. 2007. Lipase applications in food industry. Indian J. Biotechnol., 6: 141- 158.

Bankole, S.A., and Joda, A.O. 2004. Effect of lemon grass (Cymbopogon citratus Stapf.) Powder and essential oil on mould deterioration and aflatoxin contamination of melon seeds (Colosynthis citrulus L.). African J. Biotechnol., 3: 52-59.

Bhattacharya, K., and Raha,S. 2004. Deteriorative changes of maize, groundnut and soyabean seeds by fungi in storage. Mycopathologia, 155: 135-141.

Colen, G., Junqueira, R.G., Moraes-Santos, T. 
2006. Isolation and screening of alkaline lipase-producing fungi from Brazilian savanna soil. World J. Microbiol. Biotechnol., 22: 881- 885.

Godfredson, S.E., Fogarty, W.M., Kelly, E.T. 1990. Microbial enzymes and biotechnology. Elsevier Applied Sciences. The Netherlands. 255-73.

Gopinath, S.C.B., Anbu, P., Lakshmipriya, T. and Hilda, A. 2013. Strategies to characterize fungal lipases for applications in medicine and dairy industry. BioMed Res. Int., 1-10.

Gupta, R., Rathi, P., Gupta, N., Bradoo, S. 2003. Lipase assay for conventional and molecular screening: an overview. Biotechnol. Appl. Biochem., 37: 63-71.

Iftikhar, T. and Hussain, A. 2002. Effect of nutrients on the extracellular lipase production by the mutant strain of $R$. oligosporousTuv-31. Biotech., 1(1): 15-20.

Johnson, L.F., Curl, E.A., Bond, J.H., Friburg, H.A.1959. Microorganism in the plant rhizosphere. In: Johnson LF, Curl LF (Eds.) methods for studying soil microflora- plant disease relationship. Burgess Publi. Minn. pp: 29-37.

Joseph, B., Ramteke, P.W., Thomas, G. 2008. Cold active microbial lipases: Some hot issues and recent developments. Biotechnol. Adv., 26: 457-470.

Mateos, Diaz, J.C., Rodríguez, J.A., Roussos, S., Cordova, J., Abousalham, A., Carriere, F., Baratti, J. 2006. Lipase from the thermotolerant fungus Rhizopus homothallicus is more thermostable when produced using solid state fermentation than liquid fermentation procedures, Enzyme Microb. Technol., 39: 1042-1050.

Negedu, A., Dapiya, S.H., Wartu, J.R., and Migap,H.H. 2010.Biodeterioration of Soya bean oil by mesophilic moulds. Biol. Environ. Sci. J. Tropics, 7 (3): 113-118.

Reetz, M.T. 2002. Lipases as practical biocatalysts. Curr. Opin. Chem. Biol., 6: 145-150.

Saxena, R.K., Ghosh, P.K., Gupta, R., Davidson, W.S., Bradoo, S. and Gulati, R. 1999. Microbial lipases: Potential biocatalysts for the future industry. Curr. Sci., 77(1): 101-115.

Sharma, R., Chisti, Y., and Banerjee, U. 2001. Production, purification, characterization and applications of lipases. Biotechnol. Adv., 19: 627-662.

Sierra, G. 1957. A simple method for the detection of lipolytic activity of microorganisms and some observations on the influence of the contact between cells and fatty substrates. Antonie van Leeuwenhoek. 23:15-22.

Singh, A.K., and Mukhopadhyay, M. 2012. Overview of fungal lipase: A Review. Appl. Biochem. Biotechnol., 166: 486-520.

Thomas, S.B., Thomas, B.F. 1973. Psychrotrophic bacteria in refrigerated bulk-collected raw milk. Part II Dairy Ind., 38: $61-70$

Treichel, H.D. Oliveira, de., Mazutti, M.A., Di Luccio, M., Oliveira, J.V. 2012. A review on microbial lipases production. Food Bioprocess Technol., 3: 182-196.

\section{How to cite this article:}

Toshi Wadia and Sudhir Kumar Jain. 2017. Isolation, Screening and Identification of Lipase Producing Fungi from Oil Contaminated Soil of Shani Mandir Ujjain. Int.J.Curr.Microbiol.App.Sci. 6(7): 1872-1878. doi: https://doi.org/10.20546/ijcmas.2017.607.223 